Check for updates

Cite this: J. Mater. Chem. C, 2021 , 9, 17471

Received 2nd August 2021,

Accepted 25th October 2021

DOI: $10.1039 / \mathrm{d} 1 \mathrm{tc} 03598 \mathrm{c}$

rsc.li/materials-c

\section{Low efficiency roll-off blue TADF OLEDs employing a novel acridine-pyrimidine based high triplet energy host $\dagger$}

\author{
Francesco Rodella, (D) ${ }^{a}$ Rishabh Saxena, (D) ${ }^{b}$ Sergey Bagnich, ${ }^{b}$ \\ Dovydas Banevičius, (D) c Gediminas Kreiza, ${ }^{c}$ Stavros Athanasopoulos, (D) d \\ Saulius Juršènas, ${ }^{c}$ Karolis Kazlauskas, (D) ${ }^{c}$ Anna Köhler (D) be and Peter Strohrieg ${ }^{\star a}{ }^{\text {be }}$
}

\begin{abstract}
The development of efficient blue emitter-host combinations is one of the biggest challenges in organic light-emitting diode (OLED) research. Host materials play a crucial role when it comes to enhancing the efficiency, improving the lifetime and decreasing the efficiency roll-off of the device. The need for new hosts is of prime importance, especially for blue phosphorescence and thermally activated delayed fluorescence (TADF) emitters, due to their high exciton energies. The hosts are less investigated than the emitters and require further progress. This work provides a new molecular strategy that combines an acridine derivative (donor) and pyrimidine moieties (acceptors) to obtain three novel host materials. This approach demonstrates that via careful selection of donor and acceptor units, it is possible to manage the properties of the host materials, obtaining at the same time superior thermal and morphological properties and high triplet energies up to $3.07 \mathrm{eV}$. The decrease of the conjugation in the acceptor unit was found to play a crucial role in increasing the triplet energy. The most promising host 1MPA was used to fabricate blue TADF OLEDs. Using a sky-blue emitter, we achieved electroluminescence at $491 \mathrm{~nm}$ and a maximum external quantum efficiency (EQE) of 13.6\%, combined with a low efficiency roll-off, even beyond the practical brightness of $1000 \mathrm{~cd} \mathrm{~m}^{-1}$. The host 1 MPA was also combined with a deep blue emitter to deliver a blue OLED with color coordinates of $x=0.16$ and $y=0.18$.
\end{abstract}

\section{Introduction}

Presently, organic light-emitting diodes (OLEDs) are expanding their boundaries and applications, such as in flat panel displays and smartphones, due to their significant advantages like facile preparation, cost-effectiveness, and energy efficiency. ${ }^{1,2}$ For these reasons, much effort is focused on developing this technology, both in academia and industry. Especially for display applications, commercial OLEDs contain stable and efficient green and red emitters based on iridium complexes. ${ }^{3}$ In contrast, blue emitters suffer from lacking simultaneous efficiency and

\footnotetext{
${ }^{a}$ Macromolecular Chemistry I, University of Bayreuth, Bayreuth 95440, Germany. E-mail: peter.strohriegl@uni-bayreuth.de

${ }^{b}$ Soft Matter Optoelectronics, University of Bayreuth, Bayreuth 95440, Germany ${ }^{c}$ Institute of Photonics and Nanotechnology, Vilnius University, Saulètekio av. 3 LT-10257 Vilnius, Lithuania

${ }^{d}$ Departamento de Física, Universidad Carlos III de Madrid, Avenida Universidad 30, 28911 Leganés, Madrid, Spain

${ }^{e}$ Bayreuth Institute of Macromolecular Research (BIMF), University of Bayreuth, Bayreuth 95440, Germany

$\dagger$ Electronic supplementary information (ESI) available. See DOI: 10.1039/ d1 1 c03598c
}

stability. ${ }^{4,5}$ In the last few years, thermally activated delayed fluorescence (TADF) emitters seemed to be among the most promising candidates to solve this problem. Their capacity of harvesting triplet excited states can allow for an internal quantum efficiency of up to $100 \%$ through prompt and delayed fluorescence emission. Rapid thermally activated transfer of the excitation from the triplet to the singlet state, followed by efficient delayed fluorescence, avoids degradation processes that could otherwise occur when the excitation prevails for a long time in the triplet state. TADF OLEDs contain purely organic molecules, which avoid rare and costly noble metals and allow a broad range of molecular engineering. Aside from emitters, host materials play an essential role in obtaining the desired performance of the OLED. Emitters are frequently doped in a host matrix to decrease detrimental bimolecular effects caused by longer-lived triplet states. ${ }^{6}$ The dilution into the host is thus essential to enhance the lifetime, increase the efficiency, and reduce the efficiency roll-off of the device. ${ }^{7}$ The hosts, in general, must have high and balanced charge carrier mobility, good thermal and morphological stability, and chemical stability. They also must have high triplet energy to confine the excitons on the emitter, which is particularly challenging for blue-emitting OLEDs. ${ }^{8}$ 
The majority of host materials adopt carbazole or less stable phosphine oxide groups. ${ }^{9}$ In this work, we present host molecules based on acridine and pyrimidine groups instead. Acridine is often used as a donor (D) in emitter molecules because of its rigidity and strong donating feature. ${ }^{10-13}$ Few cases report its use in hosts for red phosphorescence OLEDs. ${ }^{14,15}$ Furthermore, what brought our attention to the acridine group is that it has a higher triplet energy than carbazole (due to less conjugation). ${ }^{16}$ The pyrimidine unit is also a building block for TADF emitters due to its acceptor (A) properties. ${ }^{17-20}$ It is also used as a building block for hosts in phosphorescence OLEDs, with triplet energies of these hosts lying below $3 \mathrm{eV}^{21-23}$ Another use of pyrimidine is as an electron transport material (ETM). ${ }^{24}$

In this work, we report a strategy to obtain high triplet energy donor-acceptor host materials based on acridine and pyrimidine moieties. In particular, via careful molecular modification, it is possible to limit the conjugation of the acceptor pyrimidine, leading to a high triplet energy of more than $3 \mathrm{eV}$. To prove the strategy's applicability, we fabricated blue TADF OLEDs using the most promising host of the series (1MPA), expressing blue emission (from $461 \mathrm{~nm}$ to $493 \mathrm{~nm}$ ) with low efficiency roll-off even beyond a practical brightness of $1000 \mathrm{~cd} \mathrm{~m}^{-2}$.

\section{Experimental}

\section{Materials}

9,9-Diphenyl-9,10-dihydroacridine; 2-chloro-4,6-diphenylpyrimidine; 4,6-dichloro-2-phenylpyrimidine; 4,6-dichloro-2-methylpyrimidine; palladium(II) acetate and tri(tert-butyl)phosphine $(10 \mathrm{wt} \%$ in hexane) were purchased from abcr. Sodium tert-butoxide was purchased from TCI.

\section{Synthesis}

10-(4,6-Diphenylpyrimidin-2-yl)-9,9-diphenyl-9,10-dihydroacridine (2PPA). 9,9-Diphenyl-9,10-dihydroacridine (1 g, $3 \mathrm{mmol}, 1.1$ eq.), 2-chloro-4,6-diphenylpyrimidine ( $727 \mathrm{mg}, 2.73 \mathrm{mmol}, 1$ eq.), sodium tert-butoxide (340 mg, $3.54 \mathrm{mmol}, 1.3 \mathrm{eq}$.), palladium(II) acetate (25 mg, $0.11 \mathrm{mmol}, 0.04$ eq.) and toluene $(25 \mathrm{ml})$ were placed with a stirring bar in a Schlenk tube. The mixture was then degassed three times through freeze-pump-thaw cycles and the tube was backfilled with argon. Subsequently, tri(tertbutyl)phosphine (10 wt\% in hexane) $(0.07 \mathrm{ml}, 0.22 \mathrm{mmol}$, 0.08 eq.) was added and the mixture was then refluxed for $12 \mathrm{~h}$. The reaction mixture was extracted with water and the organic phase was dried over anhydrous sodium sulphate before evaporating the solvent with reduced pressure. Finally, the compound was purified by column chromatography on silica gel $(20 \%$ ethyl acetate/hexane) and by train sublimation, obtaining $25 \%$ yield of pure product. $1 \mathrm{H} \mathrm{NMR}\left(\mathrm{CDCl}_{3}, 500 \mathrm{MHz}, \mathrm{Me}_{4} \mathrm{Si}\right): \delta[\mathrm{ppm}] 8.01$ $(\mathrm{d}, J=7.5 \mathrm{~Hz}, 2 \mathrm{H}), 7.92(\mathrm{~d}, J=7.5 \mathrm{~Hz}, 4 \mathrm{H}), 7.45-7.42(\mathrm{~m}, 7 \mathrm{H}), 7.39$ $(\mathrm{t}, J=7.5 \mathrm{~Hz}, 2 \mathrm{H}), 7.17(\mathrm{t}, J=7.5 \mathrm{~Hz}, 2 \mathrm{H}), 7.05-6.99(\mathrm{~m}, 6 \mathrm{H})$, $6.96(\mathrm{~d}, J=7.0 \mathrm{~Hz}, 2 \mathrm{H}), 6.90$ (d, $J=6.5 \mathrm{~Hz}, 4 \mathrm{H}) .13 \mathrm{C}$ NMR $\left(\mathrm{CDCl}_{3}, 500 \mathrm{MHz}, \mathrm{Me}_{4} \mathrm{Si}\right): \delta$ [ppm] 164.21, 160.05, 144.35, 142.55,
$140.91, \quad 137.73, \quad 130.63, \quad 130.27,128.60, \quad 128.04, \quad 127.45$, $127.28,127.04,126.32,125.55,124.07,104.45,58.62$. EI-MS $m / z$ $[\mathrm{M}]^{+}: 564$.

10,10'-(2-Phenylpyrimidine-4,6-diyl)bis(9,9-diphenyl-9,10-dihydroacridine) (1PPA). 1PPA was synthesized following a similar procedure as described for 2PPA; using 9,9-Diphenyl-9,10dihydroacridine (977 mg, $2.93 \mathrm{mmol}, 2.2$ eq.), 4,6-dichloro-2phenylpyrimidine (300 mg, $1.33 \mathrm{mmol}, 1 \mathrm{eq}$.), sodium tertbutoxide (320 mg, $3.33 \mathrm{mmol}, 2.5$ eq.), palladium(II) acetate (25 mg, $0.11 \mathrm{mmol}, 0.08$ eq.), tri(tert-butyl)phosphine (10 wt\% in hexane) (0.07 ml, $0.22 \mathrm{mmol}, 0.16$ eq. $)$ and toluene $(25 \mathrm{ml})$. Yield $=28 \%$. 1H NMR $\left(\mathrm{CDCl}_{3}, 500 \mathrm{MHz}, \mathrm{Me}_{4} \mathrm{Si}\right): \delta[\mathrm{ppm}] 8.27$ (m, 2H), 7.44-7.37 (m, 7H), $7.22(\mathrm{t}, J=7.5 \mathrm{~Hz}, 4 \mathrm{H}), 7.16-7.10(\mathrm{~m}$, $12 \mathrm{H}), 7.07$ (t, $J=7.5 \mathrm{~Hz}, 4 \mathrm{H}), 6.89(\mathrm{~d}, J=7.5 \mathrm{~Hz}, 4 \mathrm{H}), 6.82(\mathrm{~d}, J=$ $7.5 \mathrm{~Hz}, 8 \mathrm{H}), 5.65$ (s, 1H). 13C NMR $\left(\mathrm{CDCl}_{3}, 500 \mathrm{MHz}, \mathrm{Me}_{4} \mathrm{Si}\right): \delta$ [ppm] 162.68, 161.44, 144.60, 140.17, 140.15, 138.37, 130.40, $130.15,128.93,128.30,128.17,127.56,126.63,126.09,123.74$, 123.69, 91.1, 58.12. EI-MS $m / z[\mathrm{M}]^{+}: 818$.

10,10'-(2-Methylpyrimidine-4,6-diyl)bis(9,9-diphenyl-9,10-dihydroacridine) (1MPA). 1MPA was synthesized following a similar procedure as described for 2PPA; using 9,9-diphenyl-9,10dihydroacridine (2.35 g, $7.05 \mathrm{mmol}, 2.3$ eq.), 4,6-dichloro-2methylpyrimidine $(0.50 \mathrm{~g}, 3.07 \mathrm{mmol}, 1 \mathrm{eq}$.), sodium tert-butoxide (0.77 g, $8.01 \mathrm{mmol}, 2.6$ eq.), palladium(II) acetate (55 mg, $0.25 \mathrm{mmol}, 0.08$ eq.), tri(tert-butyl)phosphine(10 wt\% in hexane) (0.15 ml, $0.49 \mathrm{mmol}, 0.16$ eq.) and toluene $(25 \mathrm{ml})$. Yield $=58 \%$. $1 \mathrm{H} \mathrm{NMR}\left(\mathrm{CDCl}_{3}, 500 \mathrm{MHz}, \mathrm{Me}_{4} \mathrm{Si}\right): \delta[\mathrm{ppm}] 7.23(\mathrm{~d}, J=7.5 \mathrm{~Hz}, 4 \mathrm{H})$, $7.18(\mathrm{t}, J=7.5 \mathrm{~Hz}, 4 \mathrm{H}), 7.14-7.10(\mathrm{~m}, 12 \mathrm{H}), 7.04(\mathrm{t}, J=7.5 \mathrm{~Hz}, 4 \mathrm{H})$, $6.87(\mathrm{~d}, J=7.5 \mathrm{~Hz}, 4 \mathrm{H}), 6.80(\mathrm{~d}, J=7.5 \mathrm{~Hz}, 8 \mathrm{H}), 5.60(\mathrm{~s}, 1 \mathrm{H})$, $2.43(\mathrm{~s}, 3 \mathrm{H}) .13 \mathrm{C} \mathrm{NMR}\left(\mathrm{CDCl}_{3}, 500 \mathrm{MHz}, \mathrm{Me}_{4} \mathrm{Si}\right): \delta[\mathrm{ppm}]$ $144.76,140.07,138.81,130.34,130.06,129.01,127.88,127.55$, 126.60, 126.28, 123.36, 122.31, 94.77, 57.92, 26.17. EI-MS m/z $[\mathrm{M}]^{+}: 756$.

\section{Purification}

The synthesized compounds 2PPA, 1PPA, and 1MPA were purified by train sublimation in a Carbolite split tube furnace HZS 12/450.

\section{Characterization}

${ }^{1} \mathrm{H}$ NMR and ${ }^{13} \mathrm{C}$ NMR spectra were recorded on a Bruker Avance III HD (500 MHz), the chemical shifts were referred to chloroform-d3 (7.26 ppm), and the $J$ values are given in Hz. MS spectra were obtained on a Finningan MAT 8500 using electron impact ionization.

\section{Thermal measurements}

Thermogravimetric analysis (TGA) was conducted on a Mettler TGA/DSC3 with a heating rate of $10 \mathrm{~K} \mathrm{~min}^{-1}$ under a nitrogen flow. Differential scanning calorimetry was performed with a Mettler DSC3+ in pierced $\mathrm{Al}$ pans at $10 \mathrm{~K} \mathrm{~min}^{-1}$ under a nitrogen flow. The glass transition $T_{\mathrm{g}}$ was determined as the midpoint temperature of the step. $T_{\mathrm{m}}$ and $T_{\mathrm{r}}$ were determined as the peak temperature of the melting peak and recrystallization peak, respectively. These calculations were performed by Mettler STARe 15.00a software. 


\section{Electrochemical measurements}

Cyclic voltammetry measurements were carried out using a standard three electrode electrochemical micro-cell kit from Ametek Scientific Instruments, consisting of a Platinum wire counter electrode, a Platinum disk working electrode, and a Silver/Silver chloride reference electrode. A Gamry Interface 1010T served as the potentiostat. Electrochemistry grade solvent was used, and $100 \mathrm{mM}$ tetrabutylammonium hexafluorophosphate was the supporting electrolyte. The solutions were thoroughly purged with dry nitrogen for 10 minutes before each measurement.

\section{Computational details}

We have used density functional theory to obtain the ground state geometries of the compounds employing the M06-2X exchange-correlation functional in combination with a 6-31+G(d,p) atomic basis set. Geometry optimizations were successfully converged, and no imaginary frequencies were observed following vibrational frequency analysis. Singlet and triplet emission energies were further obtained by optimizing the structures with linear response time-dependent density functional theory at the M06-2X/6-31+G(d,p) level ${ }^{25}$ and within the Tamm-Dancoff approximation. ${ }^{26}$ Electron-hole natural transition orbitals (NTOs) were calculated to characterize the excited state transitions. ${ }^{27}$ All calculations were performed using the Gaussian 16 software package, ${ }^{28}$ and orbitals were visualized using the Avogadro molecular editor software. ${ }^{29}$ Charge transfer numbers $\omega_{\mathrm{CT}}$ with values in the range between 0 (for a Frenkel exciton) and 1 (for a complete charge transfer exciton) were computed by a transition density matrix analysis, ${ }^{30,31}$ based on defragmentation of the molecules in acridine and pyrimidine groups (D-A-D for 1PPA and 1MPA and D-A for 2PPA). Electron-hole correlation plots of the $\Omega$ matrix for the excitations were also constructed based on the fragments. The average electron-hole distance $\Delta r$, based on the charge centroids of the orbitals involved in the transition, ${ }^{32}$ was also computed as a complementary indicator to the nature of the states using Multiwfn software. ${ }^{33}$

\section{Photophysical measurements}

For measurements in solution, all the compounds were dissolved in toluene or mTHF at a concentration of $6-9 \times 10^{-5} \mathrm{M}$. Solutions were sonicated for 15 minutes after preparation. Absorption spectra were recorded using a Varian Cary 5000 spectrophotometer. Fluorescence spectra, phosphorescence spectra, and room temperature (RT) photoluminescence quantum yield (PLQY) were measured using a Jasco FP-8600 spectrofluorometer. For phosphorescence measurements, the detector unit was opened at a delay of $150 \mathrm{~ms}$ after excitation, and the signal was acquired for $50 \mathrm{~ms}$. The excitation wavelength for both fluorescence and phosphorescence was $300 \mathrm{~nm}$ (unless specified in the text or figure). For the $77 \mathrm{~K}$ measurements, the sample or cuvette was immersed in liquid nitrogen. Values for the photoluminescence quantum yield of the molecules in solution were obtained using the Jasco FP-8600 spectrofluorometer equipped with an integrating sphere.

\section{OLED fabrication and characterization}

OLEDs were fabricated on pre-patterned indium tin oxide (ITO)coated glass substrates (Kintec) with an ITO layer thickness of $100 \mathrm{~nm}$ and a sheet resistance of 15-20 $\Omega \square^{-1}$. Prior to device fabrication, the substrates were cleaned by sonicating consecutively in detergent (Hellmanex II), distilled water, acetone, isopropyl alcohol, boiling distilled water, and finally treated with $\mathrm{O}_{2}$-plasma for $10 \mathrm{~min}$. The substrates were then transferred into a vacuum evaporation chamber (Vacuum Systems and Technologies Ltd) integrated inside the nitrogen-filled glove box, where the stack of organic layers was deposited at a rate of $0.5-1 \AA \mathrm{s}^{-1}$ and a pressure $<10^{-6}$ Torr. The doping of the emissive layer was accomplished by co-evaporating the host and guest materials from different evaporation sources at distinct rates for the desired doping concentration. Afterward, the samples were transported by the robotic arm to a metal deposition chamber without breaking the vacuum, which was followed by deposition of lithium fluoride (LiF) and aluminum (Al) layers at a rate of 0.2 and $2 \AA \mathrm{s}^{-1}$, respectively. The active area of the devices was $4 \mathrm{~mm}^{2}$ as defined by the ITO pattern and the shadow mask used for cathode deposition. The completed devices were removed from the vacuum chamber to the $\mathrm{N}_{2}$-filled glove box without exposure to air and encapsulated by using a glass cover and UV-curable epoxy KATIOBOND LP655 (DELO). A system consisting of a calibrated integrating sphere (ORB Optronix), a spectrometer PMA-11 (Hamamatsu), and a source-meter unit 2601A (Keithley) was utilized for evaluation of the electrical-optical properties of OLEDs such as current-voltage-luminance (I-V-L) characteristics, EQE and efficiency roll-off.

\section{Results and discussion}

\section{Design and synthesis}

In this work, a strategy to increase the triplet energy of donoracceptor molecules is shown. For this purpose, three novel host molecules were designed. As presented in previous work, ${ }^{34}$ by direct connection of donors (acridine and carbazole) and acceptors (triazine), it is possible to increase the triplet energy of donor-acceptor molecules compared to the case where the connection occurs via a conjugated bridge. In this work, acridine (donor) and three different pyrimidines (acceptors) with a different size of the conjugated system of the pyrimidine were chosen to obtain three materials of different conjugation. In particular, we aim to see a decrease in the conjugation of the acceptor moiety, a key strategy to reach a high-energy triplet (Fig. 1). 2PPA presents a donor-acceptor structure where the pyrimidine core is linked at positions 4 and 6 to two phenyl rings and at position 2 to one acridine. 1PPA has a donoracceptor-donor (DAD) structure; i.e., the pyrimidine moiety is linked to just one phenyl ring (in position 2) while two acridines occupy positions 4 and 6 . The last molecule of the series, 1MPA, still has the same DAD configuration, but the pyrimidine is substituted with a methyl group (in position 2) and two acridines (in positions 4 and 6). By replacing the phenyl ring with a methyl group, the conjugation of the 


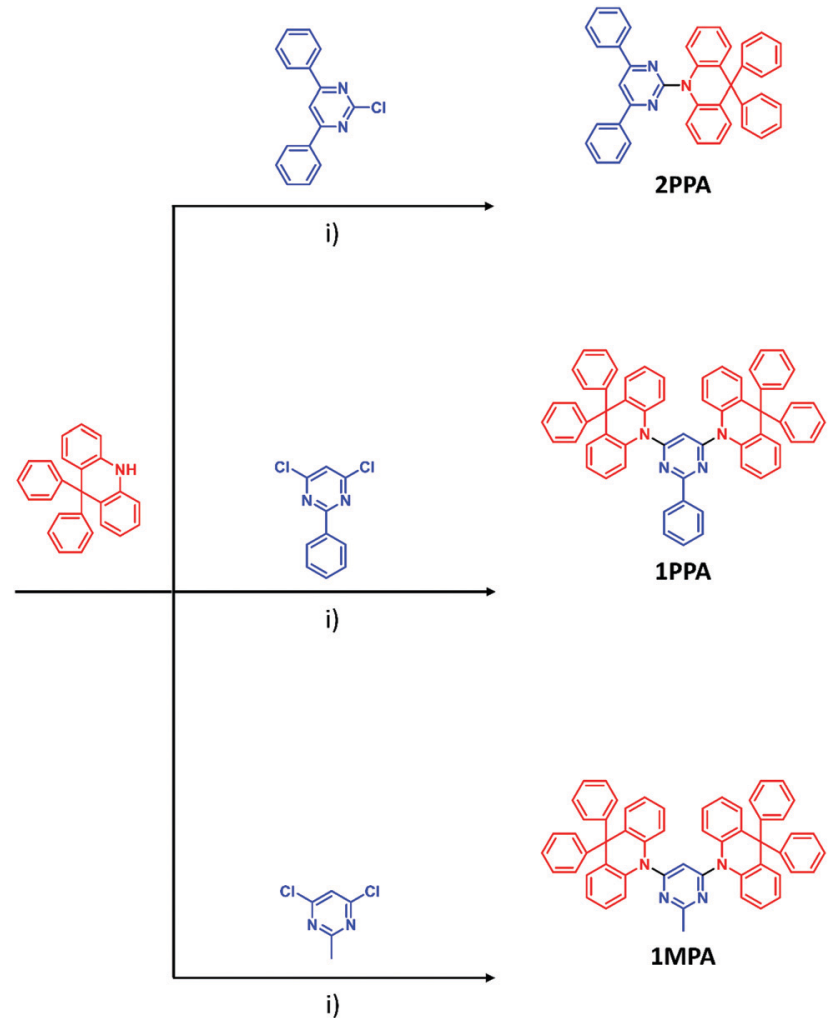

Fig. 1 Synthesis route to the three host materials 2PPA, 1PPA and 1MPA (i) $\mathrm{Pd}(\mathrm{Oac})_{2}, \mathrm{P}(t \mathrm{Bu})_{3}, \mathrm{NaOtBu}$, toluene, reflux, $12 \mathrm{~h}$.

acceptor is limited to the central pyrimidine ring. The products were synthesized using a general Buchwald-Hartwig protocol between the donor acridine and the chlorinated pyrimidine acceptor, which provides an efficient way for the formation of $\mathrm{C}-\mathrm{N}$ bonds (Fig. 1). Furthermore, all products were purified via train sublimation to obtain highly pure compounds.

\section{Thermal and electrochemical analysis}

The thermal properties of the compounds were investigated by differential scanning calorimetry (DSC) and thermogravimetric analysis (TGA), as shown in Fig. 2a and b. DSC shows that all the compounds are morphologically stable beyond $100{ }^{\circ} \mathrm{C}$ with glass transitions $\left(T_{\mathrm{g}}\right)$ of $108{ }^{\circ} \mathrm{C}\left(\right.$ (2PPA), $150{ }^{\circ} \mathrm{C}($ (1PPA), and $138{ }^{\circ} \mathrm{C}(\mathbf{1 M P A})$ and that recrystallization $\left(T_{\mathrm{r}}\right)$ upon heating occurs above $100{ }^{\circ} \mathrm{C}$ for 2 PPA and above $200{ }^{\circ} \mathrm{C}$ for 1 PPA and 1MPA, due to the addition of a second bulky acridine. The heating scan of 2PPA was obtained after the sample was melted and directly cooled with liquid nitrogen. This was necessary to obtain the amorphous material during the cooling process. The melting temperatures $\left(T_{\mathrm{m}}\right)$ are around $300^{\circ} \mathrm{C}$ for 2PPA and 1PPA and $273{ }^{\circ} \mathrm{C}$ for 1MPA.

TGA data show high decomposition temperatures $\left(T_{\mathrm{d}}\right)$ above $300{ }^{\circ} \mathrm{C}$ for 2 PPA and above $400{ }^{\circ} \mathrm{C}$ for 1PPA and 1MPA. TGA also indicates that all the materials leave none or only minor residues which means that all three hosts completely evaporate already at normal pressure, which makes them ideal candidates for OLED fabrication via evaporation. Furthermore, throughout a)
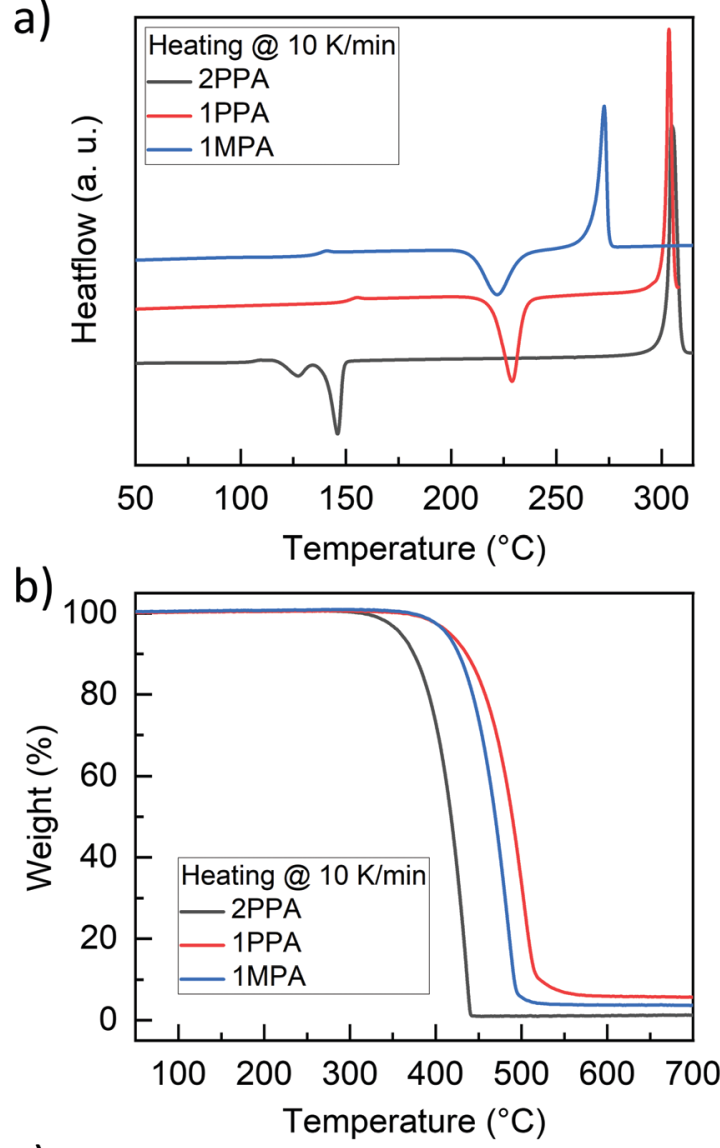

C)

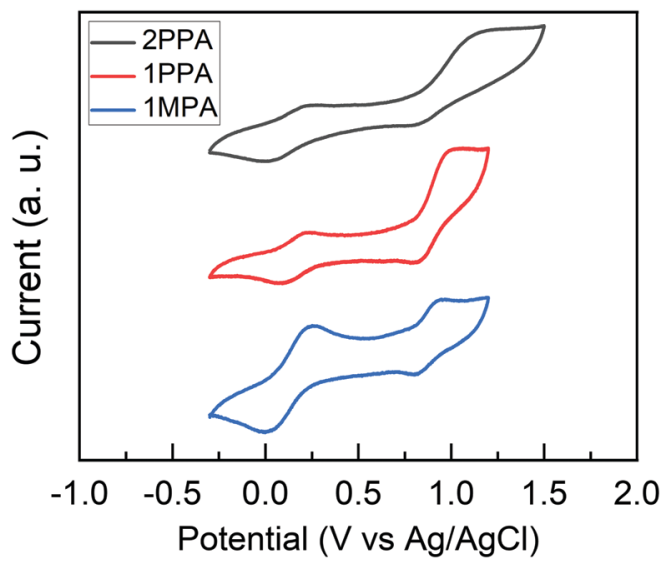

Fig. 2 Thermal and electrochemical properties of 2PPA, 1PPA and 1MPA. (a) Differential scanning calorimetry showing the second heating scan. (b) Thermogravimetric analysis. (c) Cyclic voltammograms (cathodic scan) measured in $\mathrm{CH}_{2} \mathrm{Cl}_{2}$ at room temperature with tetra- $n$-butylammonium hexafluorophosphate $(0.1 \mathrm{M})$ as the supporting electrolyte and a scan rate of $100 \mathrm{mV} \mathrm{s}^{-1}$.

the series, it is possible to see that by adding a second acridine, the $T_{\mathrm{g}}, T_{\mathrm{r}}$, and $T_{\mathrm{d}}$ values of the materials are improved. The melting points are instead similar, with a small decrease in 1MPA. These data confirm the high thermal stability of the materials and their potential applicability as hosts in OLEDs.

Furthermore, cyclic voltammetry of the three hosts was carried out to explore the electrochemical properties and to estimate the HOMO values (Fig. 2c). All the compounds show 
two quasi-reversible oxidation peaks. The first oxidation peak always appears slightly above $0.2 \mathrm{~V}$ vs. $\mathrm{Ag} / \mathrm{AgCl}$, and it corresponds to the oxidation of the acridine donor moiety. The HOMO values for the three compounds were estimated by the half-wave potential of the first oxidation potential, considering the solvent correction according to Gräf et al. ${ }^{35}$ The LUMO values were then calculated by adding the optical band gap to the HOMO values (Table 1).

\section{Absorption and photoluminescence in solution}

Absorption and photoluminescence studies of 2PPA, 1PPA, and 1MPA were performed in dilute toluene solutions to analyze their intrinsic photophysical properties, with a focus on determining their triplet state energies. Fig. 3a shows the room temperature absorption spectrum of 2PPA, 1PPA, and 1MPA. 2PPA exhibits a band attributed to CT absorption from around 3.2-3.9 eV. This assignment is based on the structureless absorption profile and comparatively low extinction of this particular band. 1PPA and 1MPA do not show any pronounced signatures of a CT state absorption. The absorption of 2PPA, 1PPA, and 1MPA differ significantly from the absorption of either donor or acceptor (Fig. S1a-c, ESI $\dagger$ ). This indicates the existence of strong electronic interactions between the donor and acceptor units in these compounds.

In order to estimate the triplet and singlet energies of the host materials, phosphorescence (Ph) and steady-state (SS) measurements were carried out at liquid nitrogen temperature (77 K). For 2PPA (Fig. 3b), the phosphorescence is structured with a $0-0$ vibrational peak at $2.81 \mathrm{eV}(442 \mathrm{~nm})$. The steady-state spectrum is a combination of fluorescence and phosphorescence as the spectrum below $2.9 \mathrm{eV}$ matches completely with the phosphorescence spectrum. Thus, the lowest singlet in 2PPA is a state exhibiting a structureless emission centered around $3 \mathrm{eV}$, with an onset at $3.15 \mathrm{eV}(394 \mathrm{~nm})$, with the lack of vibrational structure probably indicating a CT-character. In 1PPA, the lowest singlet and triplet states are both structured and have $0-0$ peaks at $3.36 \mathrm{eV}(369 \mathrm{~nm})$ and $2.76 \mathrm{eV}(449 \mathrm{~nm})$, respectively, as shown in Fig. 3c. Thus, the $T_{1}$ state is at a lower energy in 1PPA than in 2PPA. This can be accounted for by the nature of this state. The phosphorescence of 2PPA and 1PPA are similar to the ones of their respective pyrimidine acceptors (Fig. S2, ESI $\dagger$ ), indicating that the triplet is localized on the pyrimidine acceptor moieties, $2 \mathrm{PhPy}$ and $1 \mathrm{PhPy}$, in agreement with the quantum chemical calculations (vide infra). The triplet energy of the hosts therefore reflects the phosphorescence energies of the respective

Table 1 Glass transition $\left(T_{\mathrm{g}}\right)$, recrystallization $\left(T_{\mathrm{r}}\right)$, melting $\left(T_{\mathrm{m}}\right)$, and decomposition at $5 \mathrm{wt} \%$ loss $\left(T_{\mathrm{d}}\right)$ temperatures determined from differential scanning calorimetry and thermogravimetric analysis. HOMO and LUMO values of 2PPA, 1PPA, and 1MPA, calculated from cyclic voltammetry and the optical bandgap, respectively

\begin{tabular}{lllllll}
\hline & $T_{\mathrm{g}}\left({ }^{\circ} \mathrm{C}\right)$ & $T_{\mathrm{r}}\left({ }^{\circ} \mathrm{C}\right)$ & $T_{\mathrm{m}}\left({ }^{\circ} \mathrm{C}\right)$ & $T_{\mathrm{d}}\left({ }^{\circ} \mathrm{C}\right)$ & HOMO $(\mathrm{eV})$ & LUMO $(\mathrm{eV})$ \\
\hline 2PPA & 108 & 127,147 & 305 & 359 & -5.12 & -2.00 \\
1PPA & 150 & 229 & 304 & 417 & -5.11 & -1.71 \\
1MPA & 138 & 222 & 273 & 413 & -5.10 & -1.55
\end{tabular}

pyrimidine acceptors. The lower $\mathrm{T}_{1}$ energy in 1PPA results from the fact the phenyl ring is planar with the pyrimidine in 1PPA whereas there is a torsion in 2PPA, as evident in the quantum chemical calculations further below.

Due to the strong emission from the pyrimidine-based singlet state in 1PPA, we cannot discern whether there is also a CT singlet state at about $3 \mathrm{eV}$ with a lower oscillator strength buried under it. When we measured the spectra with different excitation wavelengths between $300 \mathrm{~nm}$ and $350 \mathrm{~nm}$, we found them to be independent of excitation wavelength (Fig. S3, ESI $\dagger$ ).

The emission of 1MPA, in contrast, depends on the excitation wavelength, and the corresponding spectra are shown in Fig. 3d. As before, Ph and SS measurements were carried out at $77 \mathrm{~K}$. For excitation at $300 \mathrm{~nm}$ and $320 \mathrm{~nm}(4.13 \mathrm{eV}$ and $3.88 \mathrm{eV}$, respectively), we obtain a structured phosphorescence band with a 0-0 peak at $3.18 \mathrm{eV}$. However, when exciting at $335 \mathrm{~nm}$ and at $350 \mathrm{~nm}(3.70 \mathrm{eV}$ and $3.54 \mathrm{eV})$, the emission band has a similar shape, yet it is shifted to lower energy, and it is broadened with a shoulder at $2.88 \mathrm{eV}$ and an onset at $3.07 \mathrm{eV}$. To clarify the origin of these two bands, we performed photoluminescence excitation (PLE) spectra, and we also measured the phosphorescence of the acridine donor as well as the methylpyrimidine acceptor. These data are available in the ESI $\dagger$ (Fig. S4 and S5). For the higher energy phosphorescence, two assignments are principally possible, that is, to a locally excited (LE) state localized either on the acridine donor or on the pyrimidine acceptor. Based on the data in Fig. S4 and S5 and the arguments detailed in the $\mathrm{ESI}, \dagger$ we tentatively assign the higher energy phosphorescence band to a ${ }^{3} \mathrm{LE}$ state localized on the acridine donor, and we attribute the lower energy phosphorescence band to a triplet state with mixed CT-LE character, where the LE contribution would be again from the acridine.

The fluorescence in 1MPA shows the same excitation dependence. For excitation at $300 \mathrm{~nm}$ and $320 \mathrm{~nm}$, we observe a broad band centered at about $3.6 \mathrm{eV}$ (Fig. 3e), while for excitation at $335 \mathrm{~nm}$ and $350 \mathrm{~nm}$, the fluorescence is centered at $3.0 \mathrm{eV}$ (Fig. 3f). By comparison to the acridine fluorescence spectrum (Fig. S4, ESI $\dagger$ ), the band at $3.6 \mathrm{eV}$ is readily assigned to a ${ }^{1} \mathrm{LE}$ state localized mainly on the acridine. The band at $3.0 \mathrm{eV}$, by virtue of its lower energy, must have some significant CT contribution.

We also determined the $S_{1}$ and $T_{1}$ energies of all compounds in neat films at $77 \mathrm{~K}$ and found them to be shifted to lower energies by $0.1 \mathrm{eV}$ (see Fig. S6, ESI $\dagger$ ). We attribute this rather moderate shift in the neat film to energy transfer within the DOS, which is known to be efficient in neat films, so that the emission comes from sites with lower energy within the DOS.

Fig. 4a summarizes the insights obtained on the energies and character of the excited states in 2PPA, 1PPA, and 1MPA based on the spectroscopic data. All energy values are taken from the onset of the emission spectra. It exemplifies the impact of reducing the conjugation length of the pyrimidine acceptor. While for 2PPA and 1PPA, the ${ }^{3}$ LE state localized on the 2-phenylpyrimidine (2PhPy) and 1-phenylpyrimidine $(1 \mathrm{PhPy})$ is the lowest triplet state with an onset at around $2.9 \mathrm{eV}$, this is no longer the case when the conjugation is 
a)

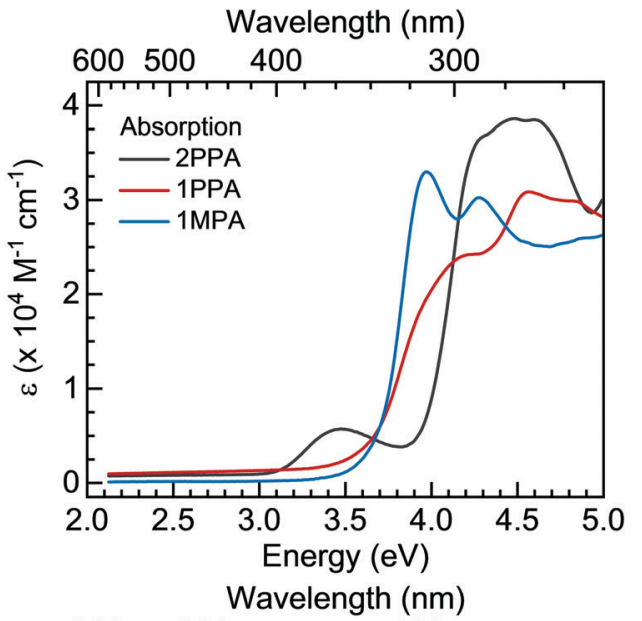

b)

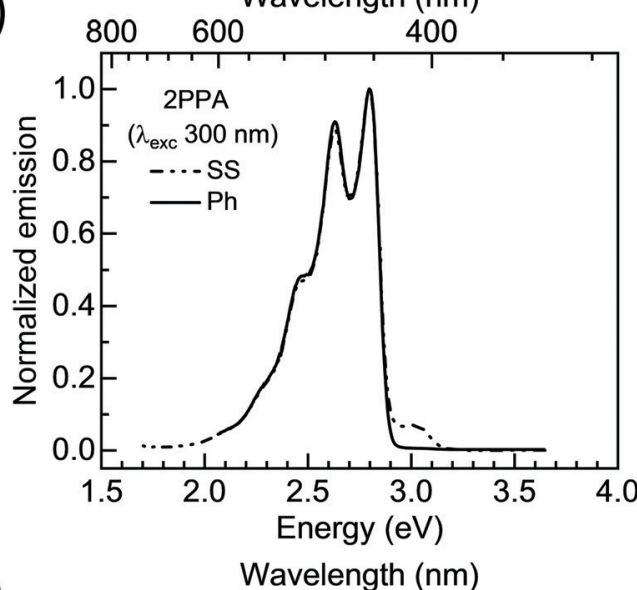

c)

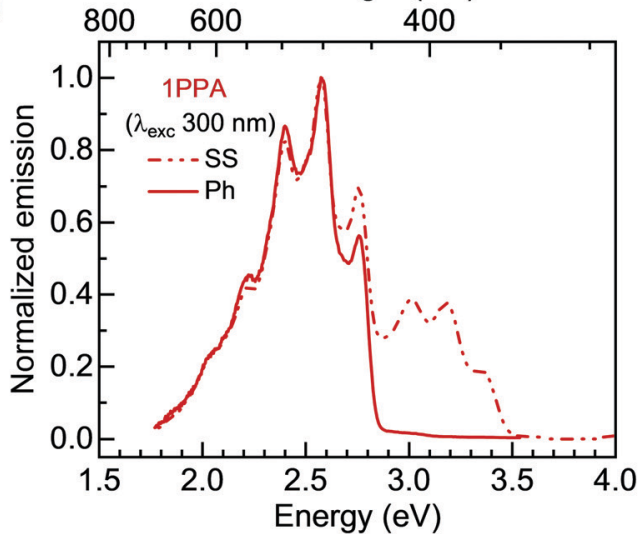

d)

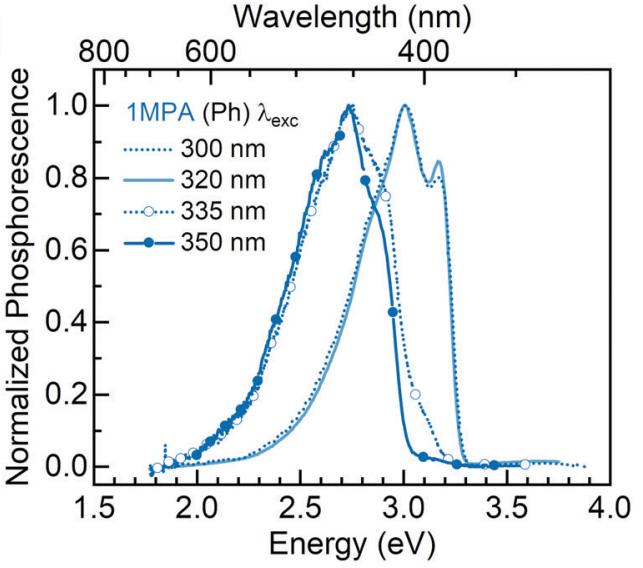

e)

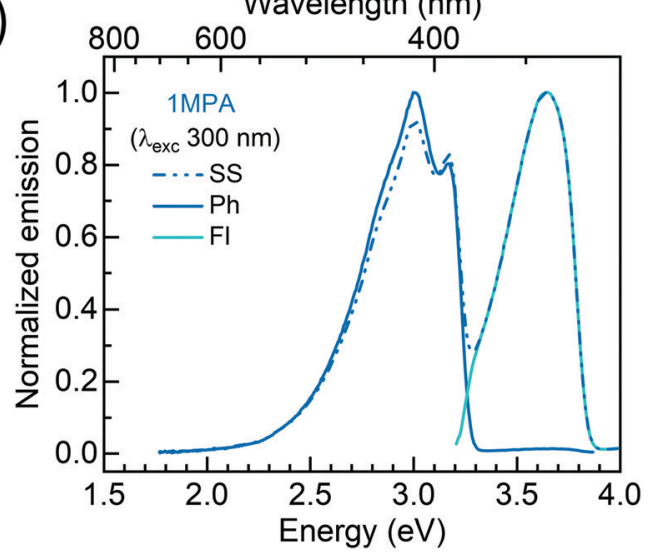

f)

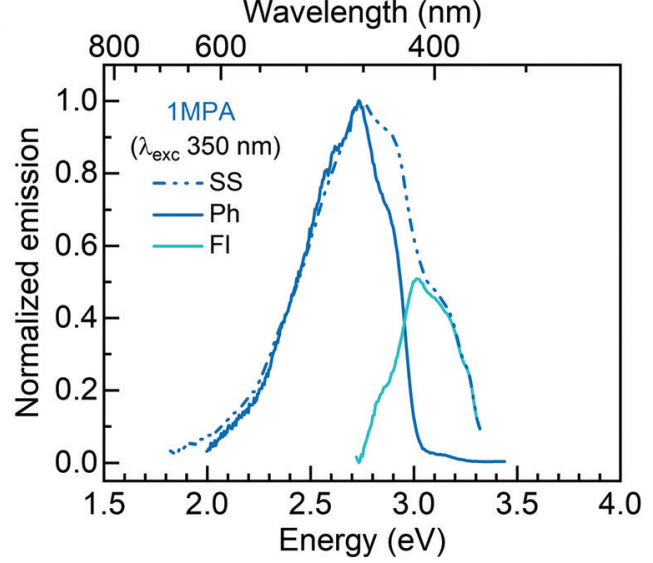

Fig. 3 (a) The absorption spectra of 2PPA, 1PPA, and 1MPA in toluene solution at $300 \mathrm{~K}$. (b) The emission spectra of 2 PPA taken at $77 \mathrm{~K}$ in a toluene glass under steady-state conditions (SS), so that both fluorescence and phosphorescence show up, and taken with a delay of $150 \mathrm{~ms}$ after excitation and a gate width of $50 \mathrm{~ms}$ so that only phosphorescence (Ph) is visible. Excitation was at $300 \mathrm{~nm}$. (c) The emission spectra were taken under the same conditions for 1PPA. (d) The phosphorescence (Ph) spectra of 1MPA in toluene glass at $77 \mathrm{~K}$, taken for different excitation wavelengths as indicated. (e) Comparison of the $\mathrm{Ph}$ and SS spectra for excitation at $300 \mathrm{~nm}$ and (f) at $350 \mathrm{~nm}$. Also indicated is the fluorescence spectrum obtained from subtracting the Ph from the SS.

reduced in methylpyrimidine (MePy). The triplet state for the units pyrimidine and methylpyrimidine have $0-0$ peaks at $3.50 \mathrm{eV}$ and $3.42 \mathrm{eV}$, respectively (see Nishi et $\mathrm{ll}^{36}$ and Fig. S5b, ESI $\dagger$ ), i.e., well above the onset of phosphorescence for the acridine moiety (Fig. S4 and S5b, ESI $\dagger$ ). As a result, in 1MPA, the lowest triplet state becomes one with a mixed CT-LE character, where the LE contribution is from the acridine unit. We also comment on the unusual observation of an excitation wavelength-dependent phosphorescence. This implies that when exciting into the acridine-based singlet LE state, the rates of intersystem crossing to its triplet state and phosphorescence can compete with the charge transfer required to form the CT-based singlet or triplet state. Evidently, the twists between the units slow down the charge transfer, which needs to take place through a bond. 

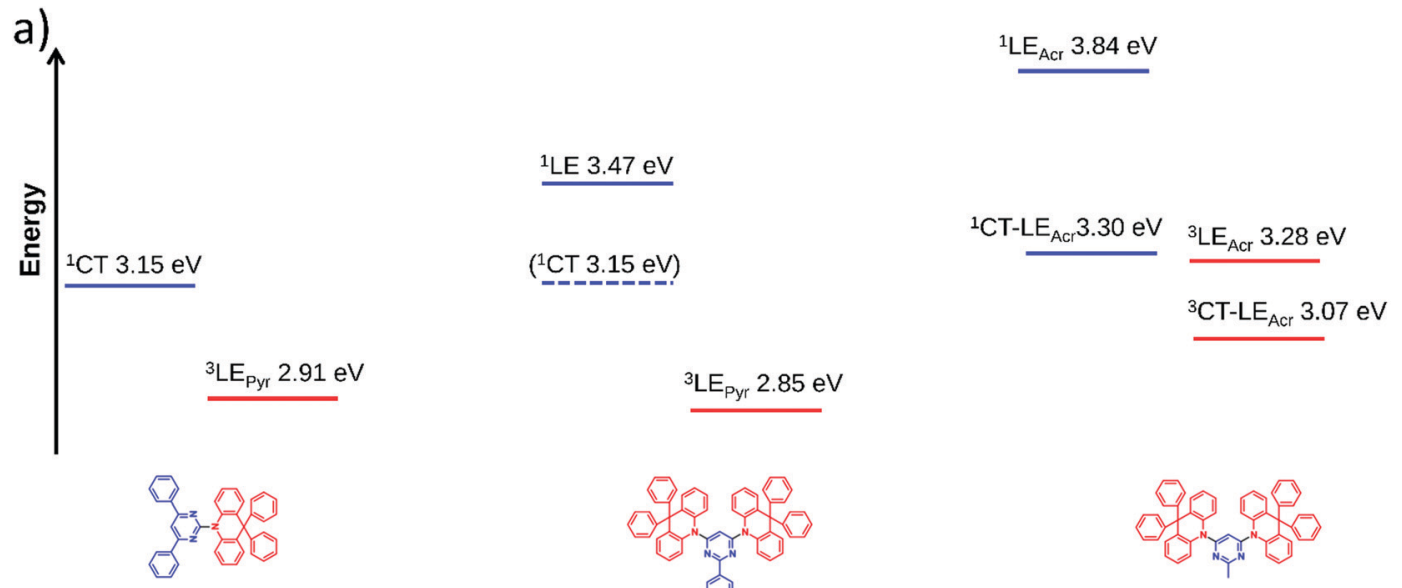

b)
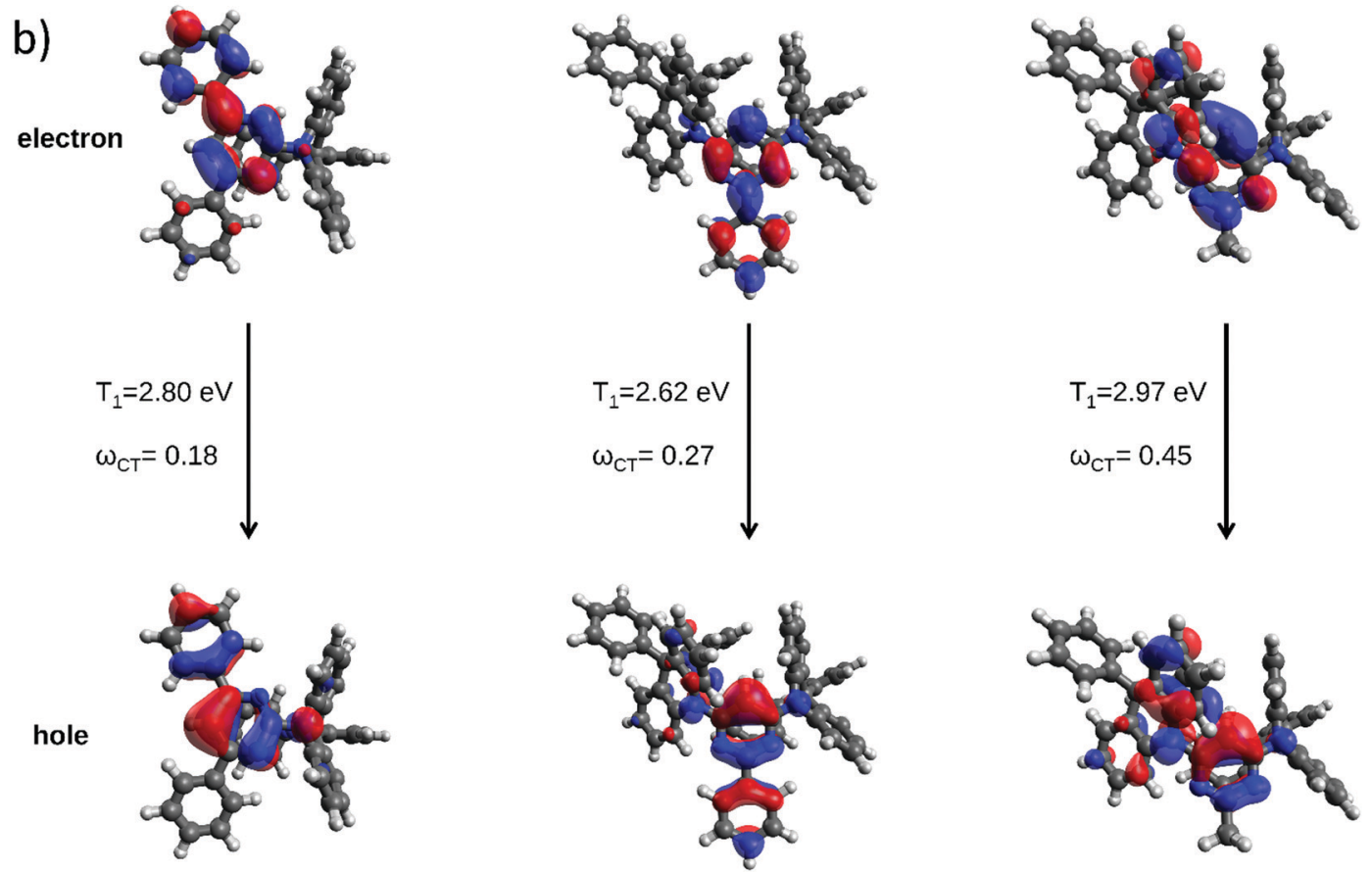

1PPA

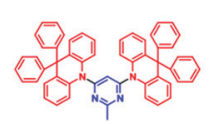

2PPA

Fig. 4 (a) Excited state energy level diagram for 2PPA, 1PPA, and 1MPA, based on the spectroscopic data, along with their structure (donor in red and acceptor in blue). The values are taken from the onset of the emission spectra. (b) TDA-DFT computed natural transition orbitals, emission energies, and charge transfer numbers for the lowest triplet state for 2PPA, 1PPA, and 1MPA at the M06-2X/6-31+G(d,p) level. Pyr represents pyrimidine acceptors and Acr the acridine donor. A side view is displayed in Fig. S8 (ESI $\dagger)$.

\section{Theoretical calculations}

For a deeper understanding of the excited states, we turn our attention to the electronic structure calculations. We find that for all molecules, acridine units lose planarity, and their central ring adopts a distorted boat conformation both at the ground and excited state geometries. This boat conformation is in agreement with results on related compounds. ${ }^{37,38}$ At the same time, there is an intramolecular pi-stacking arrangement between the phenyl ring of one of the acridine donor units and the pyrimidine acceptor moiety (Fig. S7, ESI $\dagger$ ). The obtained conformations suggest a strong electronic mixing between the donor and acceptor units, consistent with the observations made in the absorption spectra. The TDA-DFT calculated lowest excited singlet and triplet energies are in very good agreement with the fluorescence and phosphorescence spectroscopic data, respectively, as summarized in Table 2. Calculations support the above spectroscopic assignment on the nature of the emissive triplet states. Fig. $4 \mathrm{~b}$ illustrates the spatial extent of the hole-electron NTO pairs for the optimized lowest triplet state of 2PPA, 1PPA, and 1MPA, along with the calculated charge transfer numbers $\omega_{\mathrm{CT}}$. These transitions can be described by a single NTO pair. The calculated relaxed $\mathrm{T}_{1}$ state for 2PPA and 1PPA has a LE character and is localized on the pyrimidine unit, whereas the relaxed $\mathrm{T}_{1}$ state for $\mathbf{1 M P A}$ has 
Table 2 TDA-DFT computed singlet $\left(\mathrm{S}_{1} \rightarrow \mathrm{S}_{0}\right)$ and triplet $\left(\mathrm{T}_{1} \rightarrow \mathrm{S}_{0}\right)$ emission energies of 2PPA, 1PPA, and 1MPA at the M06-2X/6-31+G(d,p) level along with the energy values of fluorescence (FI) and phosphorescence $(\mathrm{Ph})$ taken from the onset of the spectra at $77 \mathrm{~K}$ in toluene solution for $300 \mathrm{~nm}$ excitation

\begin{tabular}{|c|c|c|c|c|}
\hline & Theory & Experiment & Theory & Experiment \\
\hline Compound & $\mathrm{S}_{1}(\mathrm{eV})$ & $\mathrm{S}_{1}(\mathrm{eV})$ & $\mathrm{T}_{1}(\mathrm{eV})$ & $\mathrm{T}_{1}(\mathrm{eV})$ \\
\hline 2PPA & 3.23 & 3.15 & 2.80 & 2.91 \\
\hline 1PPA & 3.41 & 3.47 & 2.62 & 2.85 \\
\hline \multirow[t]{2}{*}{ 1MPA } & $3.50\left(\mathrm{~S}_{2} \rightarrow \mathrm{S}_{0}\right)$ & 3.84 & 2.97 & 3.28 \\
\hline & $3.13\left(\mathrm{~S}_{1} \rightarrow \mathrm{S}_{0}\right)$ & $3.30^{a}$ & & $3.07^{a}$ \\
\hline
\end{tabular}

a mixed CT-LE character, with the LE part on the acridine. An energy level diagram based on the spectroscopic data is depicted in Fig. 4a. The NTOs for fluorescence can be found in Fig. S7 (ESI $\dagger$ ). The emissive singlet for 2PPA is localized on the pyrimidine, which is in contrast to the spectroscopic assignment of a CT state. This comes from the fact that the obtained gas-phase geometry from the TDA-DFT calculations leads to a distorted acridine. However, in the solid state, intermolecular interactions might favor pi-pi stacking configurations between the acridine units of the molecules and result in a twisted intramolecular CT state. For 1PPA, the obtained lowest singlet is at $3.41 \mathrm{eV}$ and has a CT character. The lowest singlet state for 1MPA is at $3.13 \mathrm{eV}$, which displays a strong charge transfer character as depicted by the hole-electron pair natural transition orbitals and the electron-hole correlation plot of the $\boldsymbol{\Omega}$ matrix (Fig. S9, ESI $\dagger$ ) and has a weak oscillator strength $f=0.0037$. Following optimization of the second lowest singlet state, $\mathrm{S}_{2}$, we find that it is located at $3.50 \mathrm{eV}$ and has an oscillator strength $f=0.0134$ (Fig. S7, ESI $\dagger$ ). Although the charge transfer numbers obtained are similar for the two states, the electron-hole distance index $\Delta r$ is larger for the $\mathrm{S}_{1}$ state $(\Delta r=3.26 \AA)$ than for the $\mathrm{S}_{2}$ state $(\Delta r=2.07 \AA)$, indicating a larger CT length for the $S_{1}$ state. The hole NTO for $S_{2}$ is delocalized across both acridine units. This could explain the experimentally observed excitation wavelength dependent emission described in the previous section. Given the relatively large energy difference between the $S_{2}$ and $S_{1}$ states and the fact that relaxation from the Franck-Condon state requires large conformational rearrangement, vibrational relaxation and internal conversion to $S_{1}$ might compete with radiative emission from the $\mathrm{S}_{2}$ state leading to non-Kasha emission. ${ }^{39}$

\section{OLED properties}

After having established that the acridine-pyrimidine based compound 1MPA is the one with the highest triplet energy $(>3.0 \mathrm{eV})$ among the studied compounds, we employed it as a host for the fabrication of blue OLED. We combined it with the previously reported blue TADF emitters $\mathbf{M P T C}^{40}$ and OBA-O ${ }^{41}$ as dopants (Fig. S10e, ESI $\dagger$ ). In the case of mPTC, a doping concentration of $12 \mathrm{wt} \%$ was used based on photoluminescence quantum yield measurements (Table S1, ESI $\dagger$ ). For the emitter OBA-O we used several doping concentrations $(5,8$, and $13 \mathrm{wt} \%)$ with a view to examine the emission wavelength tunability of the device. The choice of MPTC and OBA-O as TADF emitters was based on (i) their shallow HOMO levels $(-5.12$ and $-5.15 \mathrm{eV}$, respectively), which were similar to that of $\mathbf{1 M P A}$, (ii) their triplet energies being lower than that of the host to allow for triplet exciton confinement and (iii) their high photoluminescence quantum yields. OLEDs were fabricated using the following simple device architecture: ITO $(100 \mathrm{~nm}) /$ TAPC $(30 \mathrm{~nm}) / \mathrm{EML}$ $(x$ wt $\%$ mPTC and OBA-O in 1MPA, $30 \mathrm{~nm}) / \mathrm{TmPyPB}(40 \mathrm{~nm}) / \mathrm{LiF}$ $(0.8 \mathrm{~nm}) / \mathrm{Al}(100 \mathrm{~nm})$. Here, ITO was used as a transparent anode, (1,1-bis[(di-4-tolylamino)phenyl]cyclohexane) TAPC and (1,3,5tri( $m$-pyridin-3-ylphenyl)benzene) TmPyPB for hole and electron injection/transport, respectively, $\mathrm{LiF} / \mathrm{Al}$ as the reflective cathode, whereas $x$ denotes the doping concentration (in weight percentage) of the particular TADF emitter in the emissive layer (EML).

The configuration and the energy level diagram of the device with the EML (12 wt\% mPTC in 1MPA) are displayed in Fig. 5a. The main device characteristics are provided in Fig. $5 \mathrm{~b}-\mathrm{d}$ and Table 3. The OLED demonstrated a low turn-on voltage $\left(V_{\text {on }}\right)$ of $3.25 \mathrm{~V}$, greenish-blue electroluminescence at $491 \mathrm{~nm}$ with the full width at half maximum (FWHM) of $75 \mathrm{~nm}$ resulting in Commission Internationale de L'Eclairage (CIE) coordinates of $(0.2,0.4)$. The maximum external quantum efficiency $\left(\mathrm{EQE}_{\max }\right)$ was determined to be $13.6 \%$, which is in good agreement with PLQY of MPTC in 1MPA (PLQY $\approx 70 \%$, see Table S1 of the $\left.\mathrm{ESI}^{\dagger}\right)^{40}$ if typical device outcoupling efficiency of about $20 \%$ is taken into account. ${ }^{42}$ The fabricated device exhibited low efficiency roll-off at practically useful brightness, i.e., EQE dropped down to $12.3 \%$ at the brightness of $100 \mathrm{~cd} \mathrm{~m}^{-2}$ and to $11.6 \%$ at $1000 \mathrm{~cd} \mathrm{~m}^{-2}$ (Fig. 5b). Notably, EQE remained above $10 \%$ up to the very high brightness of $5000 \mathrm{~cd} \mathrm{~m}^{-2}$. This behavior could be explained by the optimal device architecture and well-balanced electron and hole currents. The maximum luminance achieved by the device was nearly $44000 \mathrm{~cd} \mathrm{~m}^{-2}$. The properties of analogous devices based on the same host, yet the different TADF emitter OBA-O at various doping concentrations in the EML, are presented in Fig. S10 (ESI $\dagger$ ) and Table 3. The OBA-O device with a similar doping concentration (13 wt\%) as the previous one based on mPTC expressed comparable emission properties. Explicitly, peak emission wavelength, bandwidth, CIE color coordinates, and maximum EQE were found to be alike. On the other hand, the much steeper $I-V$ and $L-V$ curves in the OBA-O device indicated a significantly improved charge carrier mobility in the EML. Importantly, the reduced OBA-O concentration down to $5 \mathrm{wt} \%$ in the EML shifted the emission wavelength from greenishblue $(493 \mathrm{~nm})$ to deep-blue $(461 \mathrm{~nm})$, demonstrating the potential of 1MPA to host deep-blue TADF emitters. The picture of the deep-blue emitting OLED is shown in the inset of Fig. S10 (ESI $\dagger$ ). The reduced emitter concentration concomitantly caused a broadening of emission bandwidth (up to $94 \mathrm{~nm}$ ) and an accelerated EQE roll-off. In OLEDs, EQE roll-off typically arises from exciton-polaron quenching and from exciton-exciton annihilation. The increased roll-off with lower emitter concentrations can arise from either effect. Since there is a barrier of about $1.15 \mathrm{eV}$ for electron injection onto the host yet not for injection onto the emitter, the likely scenario is that electron transport 
a)

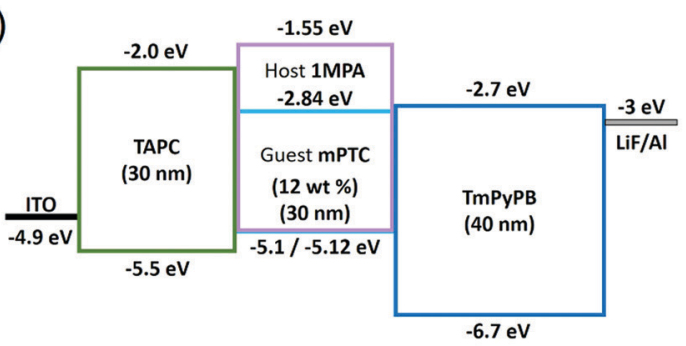

c)

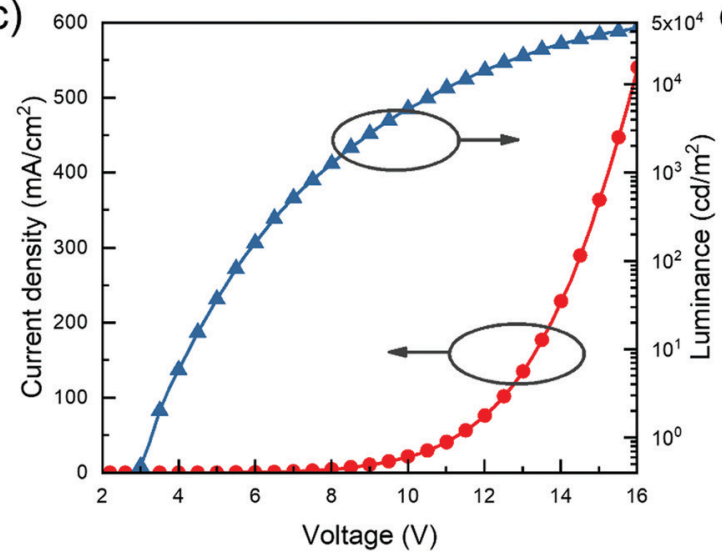

b)

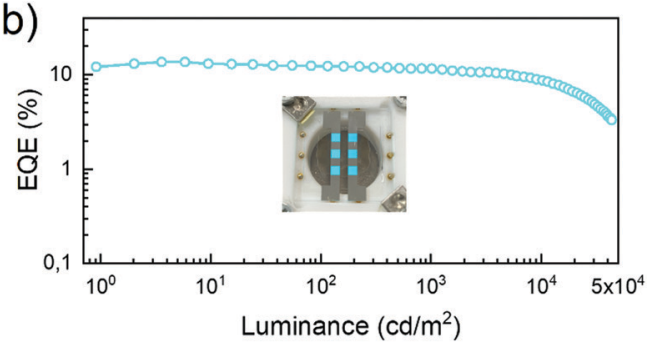

d)

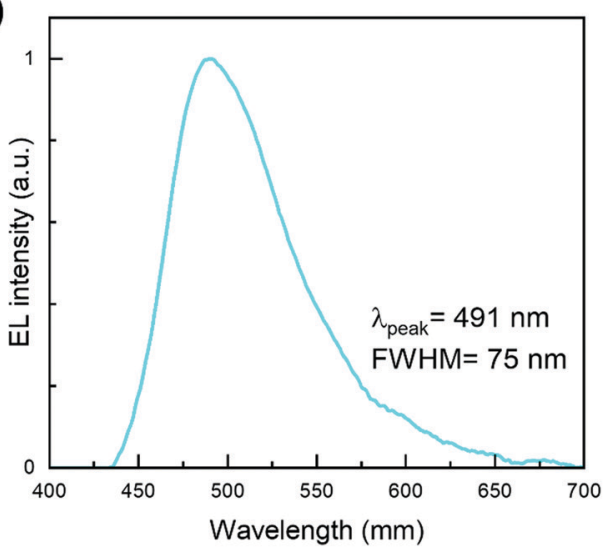

Fig. 5 Main properties of the TADF OLED based on the 1MPA host doped with 12 wt\% of $\mathbf{m P T C}$. (a) Energy level diagram. (b) EQE vs. luminance. (c) Current density and luminance vs. applied voltage. (d) Electroluminescence spectrum with working device picture shown in the inset.

Table 3 Main parameters of blue TADF OLEDs based on the 1MPA host doped with MPTC and OBA-O emitters

\begin{tabular}{|c|c|c|c|c|c|c|c|c|}
\hline Emitter & $V_{\mathrm{on}}{ }^{a}(\mathrm{~V})$ & $\mathrm{EQE}^{b}(\%)$ & $L_{\max }^{c}\left(\mathrm{~cd} \mathrm{~m}^{-2}\right)$ & $\mathrm{CE}_{\max }{ }^{d}\left(\mathrm{~cd} \mathrm{~A}^{-1}\right)$ & $\mathrm{LE}_{\max }^{e}\left(\operatorname{lm~W}{ }^{-1}\right)$ & $\lambda_{\max }^{f}(\mathrm{~nm})$ & $\mathrm{FWHM}^{g}(\mathrm{~nm})$ & $\operatorname{CIE} 1931^{h}(x, y)$ \\
\hline OBA-O (13 wt $\%$ ) & 2.75 & $14.2 / 11.9 / 8.9$ & 30247 & 36.6 & 36.4 & 493 & 83 & $(0.2,0.38)$ \\
\hline OBA-O (8 wt $\%)$ & 3.25 & $14.9 / 6.8 / 2.9$ & 8449 & 26.2 & 24.5 & 475 & 93 & $(0.16,0.21)$ \\
\hline
\end{tabular}

${ }^{a}$ Turn-on voltage at $1 \mathrm{~cd} \mathrm{~m}^{-2} .{ }^{b}$ Maximum EQE/EQE at $100 \mathrm{~cd} \mathrm{~m}^{-2} / \mathrm{EQE}$ at $1000 \mathrm{~cd} \mathrm{~m}^{-2} .{ }^{c}$ Maximum brightness. ${ }^{d}$ Maximum current efficiency. ${ }^{e}$ Maximum luminous efficiency. ${ }^{f}$ Peak emission wavelength. ${ }^{g}$ Full width at half maximum. ${ }^{h}$ Commission Internationale de L'Eclairage color coordinates $(x, y)$.

proceeds by hopping between emitter molecules while hole transport occurs via the host, where hole injection is barrier-free. This results in a charge carrier imbalance that favors exciton-hole quenching. However, at low emitter concentrations percolative transport across emitting sites is no longer possible, so that the recombination zone narrows towards the electron injecting side. This decrease in recombination zone implies an increase of both exciton and charge carrier density, so that in addition to excitonhole quenching there can also be a contribution from triplet-triplet annihilation. (see Fig. S10b, ESI $\dagger$ ). We note that the dominant lifetime of delayed fluorescence in MPTC $(2 \mu \mathrm{s})$ is shorter than that in OBA-O (9 $\mu \mathrm{s})$, consistent with its lower susceptibility to exciton quenching processes (Fig. S12 and Table S2, ESI $\dagger$ ). Furthermore, we fabricated an identical mPTC-based device where the 1MPA host is replaced with the benchmark host mCBP. In Fig. S11 (ESI $\dagger$ ) we provide the comparison of OLED properties of the two identical devices differing only by the host material (1MPA vs. benchmark mCBP). Due to the lower LUMO of MCBP compared to 1MPA, many more electrons are being injected into the mCBP host resulting in significantly higher current densities flowing through the device, and subsequently, higher luminance attained at the same driving voltage. EL spectra of both devices utilizing the same mPTC dopant concentration (12 wt\%) are found to be very similar. The device featuring benchmark mCBP host exhibits a higher EQEmax of $21 \%$ and similar efficiency roll-off as the other one based on the 1MPA host. Nevertheless, the obtained results show that high-triplet-energy host 1MPA is suitable for the fabrication of efficient blue TADF OLEDs, delivering low efficiency roll-off even beyond the practical brightness of $1000 \mathrm{~cd} \mathrm{~m}^{-2}$.

\section{Conclusions}

In this work, we present three newly synthesized host molecules that adopt acridine and pyrimidine units. The bulky acridine provides superior thermal and morphological properties, further improved when two acridines are used, like in 1PPA and 1MPA. The donor and acceptor combination allows 
transporting both holes and electrons. Throughout the series, it is possible to observe a decrease in the conjugation of the acceptor moiety within the hosts. When the acceptor unit is limited to only one pyrimidine ring (1MPA host), the triplet energy is the highest, with a value of $3.07 \mathrm{eV}$. Through theoretical calculations and spectroscopy, we attribute its nature to a mixed CT-LE state. Finally, to demonstrate the potential of these molecules, 1MPA is employed as the host material to fabricate blue TADF OLEDs. Using the emitter MPTC we achieved a skyblue OLED with electroluminescence at $491 \mathrm{~nm}$ and a maximum EQE of $13.6 \%$, combined with a low roll-off. The host 1MPA is also shown to be suitable for deep-blue emitters like OBA-O, delivering blue OLEDs with color coordinates of $x=0.16$ and $y=0.18$.

\section{Author contributions}

F. Rodella performed the synthesis and characterization of the host materials, as well as the thermal and electrochemical analysis. R. Saxena and S. Bagnich performed the photophysical studies. D. Banevičius and G. Kreiza fabricated OLED devices. S. Athanasopoulos was responsible for DFT calculations. S. Juršènas, K. Kazlauskas, A. Köhler and P. Strohriegl supervised the experiments and corrected the manuscript.

\section{Conflicts of interest}

There are no conflicts to declare.

\section{Acknowledgements}

We acknowledge funding through the EU Marie SkłodowskaCurie ITN TADFlife grant (GA. 812872). This work was also supported by Comunidad de Madrid (Spain) - multiannual agreement with UC3M ("Excelencia para el Profesorado Universitario" - EPUC3M14) - Fifth regional research plan 2016-2020 and by the Spanish Ministry of Science, Innovation and Universities (MICINN) through project RTI2018-101020-B100. The research at Vilnius University was funded by the European Social Fund (project no. 09.3.3-LMT-K-712-01-0084) under grant agreement with the Research Council of Lithuania (LMTLT).

\section{References}

1 Q. Wei, N. Fei, A. Islam, T. Lei, L. Hong, R. Peng, X. Fan, L. Chen, P. Gao and Z. Ge, Small-Molecule Emitters with High Quantum Efficiency: Mechanisms, Structures, and Applications in OLED Devices, Adv. Opt. Mater., 2018, 6, 1800512.

2 M. Y. Wong and E. Zysman-Colman, Purely Organic Thermally Activated Delayed Fluorescence Materials for Organic Light-Emitting Diodes, Adv. Mater., 2017, 29, 1605444.
3 H. Xu, R. Chen, Q. Sun, W. Lai, Q. Su, W. Huang and X. Liu, Recent progress in metal-organic complexes for optoelectronic applications, Chem. Soc. Rev., 2014, 43, 3259-3302.

4 Y. Zhang, J. Lee and S. R. Forrest, Tenfold increase in the lifetime of blue phosphorescent organic light-emitting diodes, Nat. Commun., 2014, 5, 5008.

5 Z. Xu, B. Z. Tang, Y. Wang and D. Ma, Recent advances in high performance blue organic light-emitting diodes based on fluorescence emitters, J. Mater. Chem. C, 2020, 8, 2614-2642.

6 Z. Yang, Z. Mao, Z. Xie, Y. Zhang, S. Liu, J. Zhao, J. Xu, Z. Chi and M. P. Aldred, Recent advances in organic thermally activated delayed fluorescence materials, Chem. Soc. Rev., 2017, 46, 915-1016.

7 Y. Wang, J. H. Yun, L. Wang and J. Y. Lee, High Triplet Energy Hosts for Blue Organic Light-Emitting Diodes, Adv. Funct. Mater., 2020, 2008332.

8 M. Godumala, S. Choi, M. J. Cho and D. H. Choi, Thermally activated delayed fluorescence blue dopants and hosts: from the design strategy to organic light-emitting diode applications, J. Mater. Chem. C, 2016, 4, 11355-11381.

9 T. Chatterjee and K.-T. Wong, Perspective on Host Materials for Thermally Activated Delayed Fluorescence Organic Light Emitting Diodes, Adv. Opt. Mater., 2019, 7, 1800565.

10 Q. Zhang, B. Li, S. Huang, H. Nomura, H. Tanaka and C. Adachi, Efficient blue organic light-emitting diodes employing thermally activated delayed fluorescence, Nat. Photonics, 2014, 8, 326-332.

11 T.-A. Lin, T. Chatterjee, W.-L. Tsai, W.-K. Lee, M.-J. Wu, M. Jiao, K.-C. Pan, C.-L. Yi, C.-L. Chung, K.-T. Wong and C.-C. Wu, Sky-Blue Organic Light Emitting Diode with 37\% External Quantum Efficiency Using Thermally Activated Delayed Fluorescence from Spiroacridine-Triazine Hybrid, Adv. Mater., 2016, 28, 6976-6983.

12 I. E. Serdiuk, C. H. Ryoo, K. Kozakiewicz, M. Mońka, B. Liberek and S. Y. Park, Twisted acceptors in the design of deep-blue TADF emitters: crucial role of excited-state relaxation in the photophysics of methyl-substituted $\mathrm{s}$ -triphenyltriazine derivatives, J. Mater. Chem. C, 2020, 8, 6052-6062.

13 T. Serevičius, R. Skaisgiris, I. Fiodorova, G. Kreiza, D. Banevičius, K. Kazlauskas, S. Tumkevičius and S. Juršènas, Single-exponential solid-state delayed fluorescence decay in TADF compounds with minimized conformational disorder, J. Mater. Chem. C, 2021, 9, 836-841.

14 X.-Y. Liu, F. Liang, Y. Yuan, L.-S. Cui, Z.-Q. Jiang and L.-S. Liao, An effective host material with thermally activated delayed fluorescence formed by confined conjugation for red phosphorescent organic light-emitting diodes, Chem. Commun., 2016, 52, 8149-8151.

15 X.-Y. Liu, Y.-Y. Ma, W. Zhang, B. Song, L. Ding, M.-K. Fung and J. Fan, A Novel Linking Strategy of Using 9,10Dihydroacridine to Construct Efficient Host Materials for Red Phosphorescent Organic Light-Emitting Diodes, Chemistry, 2018, 24, 11755-11762.

16 Y. Im, M. Kim, Y. J. Cho, J.-A. Seo, K. S. Yook and J. Y. Lee, Molecular Design Strategy of Organic Thermally Activated 
Delayed Fluorescence Emitters, Chem. Mater., 2017, 29, 1946-1963.

17 B. Li, Z. Li, T. Hu, Y. Zhang, Y. Wang, Y. Yi, F. Guo and L. Zhao, Highly efficient blue organic light-emitting diodes from pyrimidine-based thermally activated delayed fluorescence emitters, J. Mater. Chem. C, 2018, 6, 2351-2359.

18 K. Wu, T. Zhang, L. Zhan, C. Zhong, S. Gong, N. Jiang, Z.-H. Lu and C. Yang, Optimizing Optoelectronic Properties of Pyrimidine-Based TADF Emitters by Changing the Substituent for Organic Light-Emitting Diodes with External Quantum Efficiency Close to 25\% and Slow Efficiency RollOff, Chemistry, 2016, 22, 10860-10866.

19 I. S. Park, J. Lee and T. Yasuda, High-performance blue organic light-emitting diodes with $20 \%$ external electroluminescence quantum efficiency based on pyrimidinecontaining thermally activated delayed fluorescence emitters, J. Mater. Chem. C, 2016, 4, 7911-7916.

20 H.-J. Park, S. H. Han and J. Y. Lee, Molecular Design of Thermally Activated Delayed-Fluorescent Emitters Using 2,2'-Bipyrimidine as the Acceptor in Donor-Acceptor Structures, Chem. - Asian J., 2017, 12, 2494-2500.

21 K. S. Son, M. Yahiro, T. Imai, H. Yoshizaki and C. Adachi, Blue organic electrophosphorescence diodes using diarylamino-substituted heterocyclic compounds as host material, J. Photopolym. Sci. Technol., 2007, 47-51.

22 S.-J. Su, C. Cai and J. Kido, RGB Phosphorescent Organic Light-Emitting Diodes by Using Host Materials with Heterocyclic Cores: Effect of Nitrogen Atom Orientations, Chem. Mater., 2011, 23, 274-284.

23 S.-J. Su, C. Cai and J. Kido, Three-carbazole-armed host materials with various cores for RGB phosphorescent organic light-emitting diodes, J. Mater. Chem., 2012, 22, 3447.

24 R. Komatsu, H. Sasabe and J. Kido, Recent progress of pyrimidine derivatives for high-performance organic lightemitting devices, J. Photonics Energy, 2018, 8, 1.

25 Y. Zhao and D. G. Truhlar, The M06 suite of density functionals for main group thermochemistry, thermochemical kinetics, noncovalent interactions, excited states, and transition elements: two new functionals and systematic testing of four M06-class functionals and 12 other functionals, Theor. Chem. Acc., 2008, 120, 215-241.

26 S. Hirata and M. Head-Gordon, Time-dependent density functional theory within the Tamm-Dancoff approximation, Chem. Phys. Lett., 1999, 291-299.

27 R. L. Martin, Natural transition orbitals, J. Chem. Phys., 2003, 118, 4775-4777.

28 M. J. Frisch, G. W. Trucks, H. B. Schlegel, G. E. Scuseria, M. A. Robb, J. R. Cheeseman, G. Scalmani, V. Barone, G. A. Petersson, H. Nakatsuji, X. Li, M. Caricato, A. V. Marenich, J. Bloino, B. G. Janesko, R. Gomperts, B. Mennucci, H. P. Hratchian, J. V. Ortiz, A. F. Izmaylov, J. L. Sonnenberg, D. Williams-Young, F. Ding, F. Lipparini, F. Egidi, J. Goings, B. Peng, A. Petrone, T. Henderson, D. Ranasinghe, V. G. Zakrzewski, J. Gao, N. Rega, G. Zheng, W. Liang, M. Hada, M. Ehara, K. Toyota,
R. Fukuda, J. Hasegawa, M. Ishida, T. Nakajima, Y. Honda, O. Kitao, H. Nakai, T. Vreven, K. Throssell, J. A. Montgomery Jr., J. E. Peralta, F. Ogliaro, M. J. Bearpark, J. J. Heyd, E. N. Brothers, K. N. Kudin, V. N. Staroverov, T. A. Keith, R. Kobayashi, J. Normand, K. Raghavachari, A. P. Rendell, J. C. Burant, S. S. Iyengar, J. Tomasi, M. Cossi, J. M. Millam, M. Klene, C. Adamo, R. Cammi, J. W. Ochterski, R. L. Martin, K. Morokuma, O. Farkas, J. B. Foresman and D. J. G. Fox, Gaussian 16, Revision C.01, Gaussian Inc., Wallingford CT, 2016.

29 M. D. Hanwell, D. E. Curtis, D. C. Lonie, T. Vandermeersch, E. Zurek and G. R. Hutchison, Avogadro: an advanced semantic chemical editor, visualization, and analysis platform, J. Cheminf., 2012, 4, 17.

30 F. Plasser, TheoDORE: A toolbox for a detailed and automated analysis of electronic excited state computations, J. Chem. Phys., 2020, 152, 84108.

31 F. Plasser and H. Lischka, Analysis of Excitonic and Charge Transfer Interactions from Quantum Chemical Calculations, J. Chem. Theory Comput., 2012, 8, 2777-2789.

32 C. A. Guido, P. Cortona, B. Mennucci and C. Adamo, On the Metric of Charge Transfer Molecular Excitations: A Simple Chemical Descriptor, J. Chem. Theory Comput., 2013, 9, 3118-3126.

33 T. Lu and F. Chen, Multiwfn: a multifunctional wavefunction analyzer, J. Comput. Chem., 2012, 33, 580-592.

34 F. Rodella, S. Bagnich, E. Duda, T. Meier, J. Kahle, S. Athanasopoulos, A. Köhler and P. Strohriegl, High Triplet Energy Host Materials for Blue TADF OLEDs-A Tool Box Approach, Front. Chem., 2020, 8, 657.

35 K. Gräf, M. A. Rahim, S. Das and M. Thelakkat, Complementary co-sensitization of an aggregating squaraine dye in solid-state dye-sensitized solar cells, Dyes Pigm., 2013, 99, 1101-1106.

36 N. Nishi, R. Shimada and Y. Kanda, The Phosphorescence Processes in Pyrimidine and 2-Chloropymidine, Bull. Chem. Soc. Jpn., 1970, 41-46.

37 G. F. Makhaeva, S. V. Lushchekina, N. P. Boltneva, O. G. Serebryakova, E. V. Rudakova, A. A. Ustyugov, S. O. Bachurin, A. V. Shchepochkin, O. N. Chupakhin, V. N. Charushin and R. J. Richardson, 9-Substituted acridine derivatives as acetylcholinesterase and butyrylcholinesterase inhibitors possessing antioxidant activity for Alzheimer's disease treatment, Bioorg. Med. Chem., 2017, 25, 5981-5994.

38 K. G. Thorat, R. P. Tayade and N. Sekar, Acridine-1, 8-diones - A new class of thermally stable NLOphores: Photophysical, (hyper)polarizability and TD-DFT studies, Opt. Mater., 2016, 62, 306-319.

39 A. P. Demchenko, V. I. Tomin and P.-T. Chou, Breaking the Kasha Rule for More Efficient Photochemistry, Chem. Rev., 2017, 117, 13353-13381.

40 D.-Y. Chen, W. Liu, C.-J. Zheng, K. Wang, F. Li, S. L. Tao, X.-M. Ou and X.-H. Zhang, Isomeric Thermally Activated Delayed Fluorescence Emitters for Color Purity-Improved Emission in Organic Light-Emitting Devices, ACS Appl. Mater. Interfaces, 2016, 8, 16791-16798.

41 D. Song, Y. Yu, L. Yue, D. Zhong, Y. Zhang, X. Yang, Y. Sun, G. Zhou and Z. Wu, Asymmetric thermally activated delayed 
fluorescence (TADF) emitters with 5,9-dioxa-13 bboranaphtho[3,2,1-de]anthracene (OBA) as the acceptor and highly efficient blue-emitting OLEDs, J. Mater. Chem. C, 2019, 7, 11953-11963.
42 N. C. Greenham, R. H. Friend and D. D. Bradley, Angular Dependence of the Emission from a Conjugated Polymer Light-Emitting Diode: Implications for efficiency calculations, Adv. Mater., 1994, 6, 491-494. 